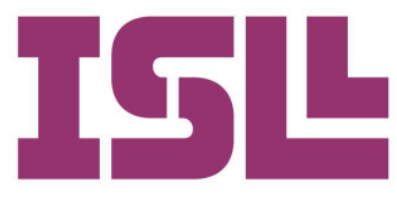

Número 5.

Enero de 2016

\section{Artes y literatura en la LOMCE: mecanismos para la comprensión de lecturas plurales}

\author{
M. ${ }^{a}$ Isabel Vicente-Yagüe Jara \\ Universidad de Murcia
}

Pág. 59 a la 69

\section{Keywords}

Literature, Arts, reading, LOMCE, reader intertext

\section{Abstract:}

The current curriculum in Compulsory Secondary Education within the LOMCE law evidences the existing connection between the different artistic expressions. Specifically in the literary subjects, it is aimed to promote the consideration of the links between Literature and the rest of arts (Music, Painting, Cinema...) as an expression of the human feelings, while analyzing and interrelating works, characters and plots from all the time periods.

Aesthetics, Rhetoric, Poetry, Fine Arts, Musicology, Semiotic, the Comparative Literature, and Criticism, as disciplines interested in the foresaid pairing, have just joint their studies, examining, from a theoretical approach, the existing links and transpositions between arts. In the educational field, establishing analogies and intersections between arts is conceived as a process for understanding the literary works: the didactic use of the semiotic correspondences for showing an interconnected reality of multiple readings in the classroom.
From that perspective, a literary hypertext allows non lineal readings, through its links and connections with other texts, enhancing the student's reception and leading it towards multiple and significant realities. In that sense, the literary work, in where several possible reading itineraries coincide all together, acquires an open character, losing its consideration of being close and concluded. Hereby, we specify the type of activities, works and reading mechanisms that the new curricular approach requires; ekphrasis, melopoiesis, and Literature in films, among other dialogic links, that are a reclaim for the reading process in students while strengthening their aesthetical reception skills. In the same way, the theories about the reader intertext, linked to the literary training of students and the development of their reading comprehension, set the standards of the teaching methodology in the classroom. 


\section{La LOMCE y las artes}

El actual currículo de Educación Secundaria Obligatoria en el marco de la LOMCE pone de manifiesto la conexión entre las distintas expresiones artísticas. Concretamente, en las materias literarias se pretende la reflexión sobre la relación entre la literatura y el resto de las artes, a partir de ciertos criterios de evaluación y estándares de aprendizaje. Hasta este momento, los currículos anteriores no habían reflejado de manera tan explícita esta vinculación de las artes en la materia de Lengua Castellana y Literatura, aunque en las prácticas habituales de algunos docentes sí pudieran ser recogidas ciertas experiencias interdisciplinares (Guerrero, 2008; Mendoza, 2012; Vicente-Yagüe, 2013; Romea, 2011).

En este sentido, en el bloque 4 dedicado a "Educación literaria", se puede leer el siguiente criterio de evaluación establecido para el primer ciclo y el cuarto curso (MECD, 2015, p. 364, 370):

- Promover la reflexión sobre la conexión entre la literatura y el resto de las artes: música, pintura, cine, etc., como expresión del sentimiento humano, analizando e interrelacionando obras (literarias, musicales, arquitectónicas...), personajes, temas, etc. de todas las épocas.

De igual forma, los estándares de aprendizaje evaluables relacionados con el mencionado criterio se concretan en los siguientes términos (MECD, 2015, p. 364, 370):

- Desarrolla progresivamente la capacidad de reflexión observando, analizando y explicando la relación existente entre diversas manifestaciones artísticas de todas las épocas (música, pintura, cine...)

- Reconoce y comenta la pervivencia o evolución de personajes-tipo, temas y formas a lo largo de diversos periodos histórico/literarios hasta la actualidad.

- Compara textos literarios y piezas de los medios de comunicación que respondan a un mismo tópico, observando, analizando y explicando los diferentes puntos de vista según el medio, la época o la cultura y valorando y criticando lo que lee o ve.

A su vez, la materia de Literatura Universal de $2^{\circ}$ de Bachillerato presenta en su bloque 1 dedicado a "Procesos y estrategias" criterios de evaluación similares (MECD, 2015, p. 379):

- Interpretar obras narrativas, líricas y dramáticas de la literatura universal especialmente significativas relacionando su forma y su contenido con las ideas estéticas dominantes del momento en que se escribieron y las transformaciones artísticas e históricas producidas en el resto de las artes. 
- Observar, reconocer y valorar la evolución de algunos temas y formas creados por la literatura y su valor permanente en diversas manifestaciones artísticas de la cultura universal.

En la misma línea interdisciplinar, destaca también el estándar de aprendizaje evaluable del bloque 2, "Los grandes períodos y movimientos de la literatura universal" (MECD, 2015, p. 380):

- Explica oralmente o por escrito los cambios significativos en la concepción de la literatura y de los géneros literarios, relacionándolos con el conjunto de circunstancias históricas, sociales y culturales y estableciendo relaciones entre la literatura y el resto de las artes.

Por otra parte, este propósito interdisciplinar ya era recogido por otras materias artísticas como la Música en las anteriores disposiciones normativas. Así también, el actual Real Decreto 1105/2014, con el mismo sentir metodológico, establece en la etapa de Educación Secundaria Obligatoria los siguientes criterios de evaluación, dirigidos respectivamente al primer ciclo y al cuarto curso:

- Realizar ejercicios que reflejen la relación de la música con otras disciplinas (MECD, 2015, p. 510).

- Relacionar la música con otras manifestaciones artísticas (MECD, 2015, p. 511).

Se comprueba de esta manera el interés explícito del currículo en las múltiples conexiones literario-artísticas desde las diferentes disciplinas educativas implicadas.

\section{Literatura, música, pintura y cine: correspondencias semióticas}

La Estética, la Retórica, la Poética, las Bellas Artes, la Musicología, la Semiótica, la Literatura Comparada y la Crítica ya han ido tendiendo lazos en sus estudios, examinando los vínculos y transposiciones existentes entre las artes desde un punto de vista teórico. Además, se debe señalar que hoy en día la investigación sobre las correspondencias entre las artes no ha perdido su interés y actualidad, como demuestran publicaciones recientes (Ergal y Finck, 2014).

Clásico es ya el círculo de Etienne Souriau (1998, p. 122) acerca de la correspondencia de las artes, en el que a partir de siete qualias o grupos de cualidades sensibles distingue entre las artes de primer grado y las artes de segundo grado, delimitadas por los mismos radios en un segundo círculo concéntrico. 
1. Líneas

2. Volúmenes

3. Colores

4. Luminosidades

5. Movimientos

6. Sonidos articulados

7. Sonidos musicales

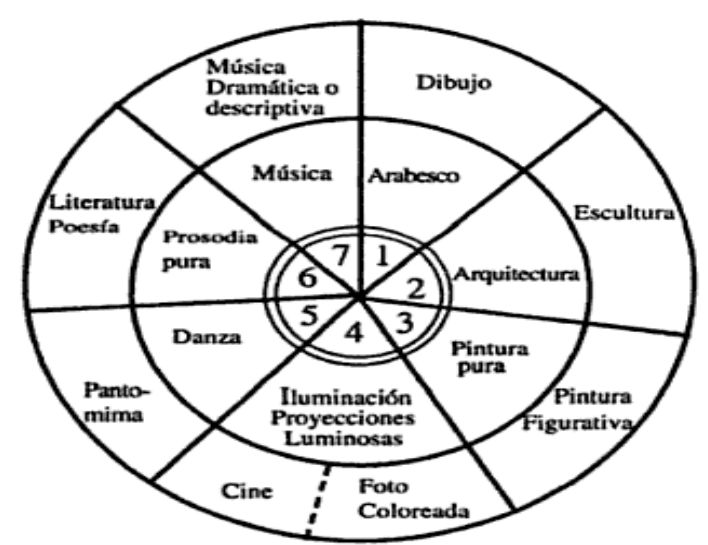

Figura 1. Correspondencias de las artes (Souriau, 1998, p. 122)

Pese a gozar de fama en las investigaciones interartísticas, dicha propuesta no está exenta de problemas según los teóricos. En esta línea, resulta de gran interés por el entramado metadiscursivo que presenta el sistema alternativo de intersecciones planteado por Victoria Llort (2011, pp. 91-101) en La memoria de las musas. Mientras que el esquema de Souriau aleja a las artes de su centro de gravedad, al avanzar por cada círculo en un movimiento centrífugo, el sistema de Llort procura reunirlas, según ella misma afirma. Se nos ofrece aquí una nueva e interesante vía de estudio interdisciplinar, que da cuenta de los procesos transartísticos y prepara metodológicamente un significativo acercamiento a las fases de comprensión e interpretación artística.

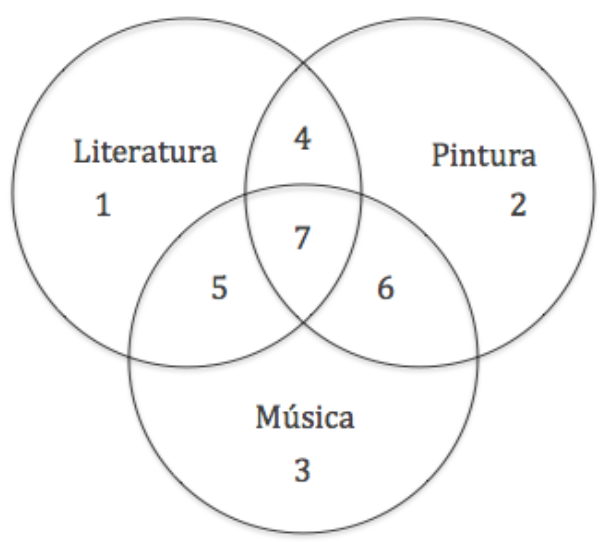

Figura 2. Intersecciones entre las artes (Llort, 2011, p. 92)

Lo verbal, lo visual y lo sonoro son las unidades básicas a partir de las cuales es posible diferenciar espacios puros e intersecciones de dos o tres artes. Estas correspondencias semióticas o confluencia de lenguajes en las obras ubicadas en las intersecciones son las que realmente interesan en las disposiciones normativas, preocupadas por trabajar lecturas plurales y establecer mecanismos de recepción interconectados. Veamos a continuación los conjuntos resultantes en la figura 2, así como 
algunas de las creaciones artísticas que ilustran especialmente los últimos puntos de intersección y recepción plural:

1. Literatura pura.

2. Pintura pura.

3. Música pura.

4. Intersección literatura-pintura: A la pintura de Rafael Alberti, Paseo de Cieza (Murcia) de José Lucas.

5. Intersección literatura-música: poema sinfónico Don Quijote de R. Strauss.

6. Intersección pintura-música: Cuadros de una exposición de Mussorgsky.

7. Triple intersección literatura-pintura-música: ópera Don Giovanni de Mozart.

Se comprueba cómo la triple intersección responde a la obra de arte total ya prevista por Wagner (1952). De este modo, la ópera constituye una creación mixta en la que se dan cita diferentes elementos y manifestaciones artísticas: música, libreto, artes escénicas, escenografía (pintura, decoración), iluminación, vestuario y maquillaje...

\section{Mecanismos de recepción en el aula}

En el ámbito educativo, el establecimiento de analogías e intersecciones entre las artes debe entenderse principalmente como un medio dirigido a la comprensión de las obras literarias: la explotación didáctica de las correspondencias semióticas para mostrar en el aula una realidad interconectada de lecturas plurales. Desde esta perspectiva, una obra literaria hipertextual permite lecturas no lineales, a través de sus vínculos o anclajes con otros textos que enriquecen la recepción del alumno y la dirigen hacia múltiples realidades significativas (Mendoza, 2012). La obra literaria adquiere así un carácter abierto y pierde la consideración de cerrada o concluida, al coincidir en ella diferentes itinerarios de lectura posibles.

Acorde con estas necesidades normativas y en respuesta a la tradición artística existente, algunos de los libros de texto de la materia de Lengua Castellana y Literatura que han ido surgiendo en el nuevo marco curricular de la LOMCE ya han incluido las artes como novedad en sus guías de contenidos (Benítez, Vicente-Yagüe, Jiménez, Sánchez, 2015a; Benítez, Vicente-Yagüe, Jiménez, Sánchez, 2015b).

Asimismo, las teorías del intertexto lector (Mendoza, 2001) en conexión con la formación literaria del alumno y el desarrollo de su competencia lectora marcan las pautas de actuación metodológica del docente en el aula. En el proceso de recepción se activan las estrategias, los conocimientos y las experiencias previas del individuo y, por ello, la amplitud del intertexto, como espacio de encuentro de las aportaciones del texto con las 
del lector, es decisiva en la identificación, asociación y conexión de los elementos leídos, escuchados u observados en el texto plural.

A continuación, se concretan el tipo de actividades, obras y mecanismos lectores que requiere el nuevo enfoque curricular. Se ha de apostar por incluir estas lecturas plurales en el canon de aula seleccionado por el docente en el marco de su actividad habitual (Vicente-Yagüe, 2015a). Ékfrasis, melopoiesis y cine de literatura, entre otras relaciones dialógicas, constituyen un reclamo en la tarea lectora del estudiante, potencian sus habilidades de recepción estética y procuran dirigirse especialmente hacia los niveles emocional y creador de comprensión lectora planteados por Jiménez (2015).

\subsection{Melopoiesis}

Los lenguajes literario y musical permiten ser trabajados a través de diferentes géneros mixtos que recrean y toman elementos de la literatura: música programática, cuento musical, canción, ópera... Esta estética intersemiótica fue acuñada con el término de melopoiesis por Barricelli (1988) y se fundamenta en la simbiosis artística de sus términos dialogantes: música y poesía. Diversos han sido los estudios que en el ámbito didáctico han procurado el trabajo de la intertextualidad literario-musical dirigida al desarrollo de las competencias literaria y artística, demostrando en los resultados obtenidos la validez y eficacia de los modelos y metodologías interdisciplinares empleadas (Vicente-Yagüe, 2013, 2015b).

Entre las obras posibles de estudio en las aulas, fruto del mencionado diálogo melopoético, se destacan las siguientes:

- Poema sinfónico Mazeppa de Franz Liszt. Hipotexto: Victor Hugo.

- Poema sinfónico El aprendiz de brujo de Paul Dukas. Hipotexto: balada de J.W. Goethe.

- Lied "Por una mirada un mundo" de E. Granados. Hipotexto: G.A. Bécquer.

- Romancero gitano de Mario Castelnuovo-Tedesco. Hipotexto: F. García Lorca.

- Cuento musical L'histoire de Babar, le petit éléphant de F. Poulenc. Hipotexto: Jean de Brunhof.

- "Hoy converso con Miguel” de Nach. Hipotexto: Miguel Hernández.

- “Canción del pirata” de Tierra Santa. Hipotexto: José de Espronceda.

Los mecanismos lectores que se activan en la recepción de este tipo de obras permiten la realización de una serie de tareas creativas e interpretativas de interacción intertextual:

- Reconocimiento de la caracterización sonora y psicológica de lugares, personajes, acciones y tiempos de la obra literaria. 
- Identificación de las metáforas musicales en las composiciones, con el fin de enriquecer y ampliar el intertexto lector.

- Comprensión de la estructura del texto literario a través de la escucha musical: motivos rítmicos, elementos melódicos recurrentes, variaciones, modulaciones...

- Dramatización e improvisación de la obra literaria como acto espontáneo de comprensión textual.

- Tareas de escritura poética, que potencian la creatividad y que permiten el desarrollo de estrategias de producción hipertextual a partir de referentes intertextuales musicales.

\section{2. Ékfrasis}

A lo largo de la historia, los préstamos entre la literatura y la pintura se han manifestado en diferentes obras de inspiración mixta que han perseguido la actualización creativa del receptor (Bergez, 2011). De esta manera, el lector o el observador de un cuadro se convierte en co-creador de las obras, al descubrir, reconocer y activar las relaciones de intertextualidad previstas por su autor. El enunciado horaciano Ut pictura poiesis y el concepto de la ékfrasis se erigen como eficaces recursos en el terreno didáctico para la comprensión e interpretación de los textos (Guerrero, 2008). En ocasiones, la paleta poética de un escritor ya ha permitido una visual y colorista descripción de la realidad literaria (Benítez, 2003).

Algunas de las obras en las que se advierte este doble juego hermenéutico y a través de las cuales realizamos auténticas "lecturas de museo" (Mendoza, 2000) son las siguientes:

- "Mujer llorando" de R. Alberti. Hipotexto: La mujer que llora de P. Picasso.

- "Las lanzas de Velázquez" (Horas de oro) de Manuel Machado. Hipotexto: La rendición de Breda de D. Velázquez.

- "Óleo (Niño de Vallecas)" de V. Aleixandre. Hipotexto: El niño de Vallecas de D. Velázquez.

- Don Quixote de P. Picasso. Hipotexto: Miguel de Cervantes.

- La Celestina de P. Picasso. Hipotexto: Tragicomedia de Calisto y Melibea.

- Margarita ante el espejo de Domínguez. Hipotexto: Fausto de J.W. Goethe.

A continuación, se presentan una serie de tareas y propuestas didácticas dirigidas a la recepción de los textos artísticos que dialogan y se reclaman en su trayectoria cultural:

- Taller de escritura poética tras la observación de una obra plástica, dirigido a la descripción de ambientes y personajes o a la narración de situaciones en un tiempo y un espacio determinado. 
- Ilustración de poemas o cuentos, con el fin de completar de manera creativa lo insinuado o descrito por las palabras en un texto literario.

- Análisis de un mismo elemento (personaje, objeto, escenario...) en su diferentes representaciones según los códigos plásticos y literarios empleados: analogías, diferencias, variaciones...

- Comentarios críticos, asociación de ideas y sensaciones generadas a partir de la "lectura" de un cuadro.

- Taller de narrativa en el que se crea una historia apoyada en una serie de imágenes artísticas y secuenciada al modo de Mussorgsky en sus Cuadros de una exposición.

\subsection{Cine de literatura}

En este punto resulta de obligada mención el blog Cine de literatura de Celia Romea Castro, en el que su autora analiza las conexiones intertextuales que ofrecen el cine y la literatura, acompañadas de sugerencias didácticas que nos permiten "aprender a ver cine y mejorar la lectura". Resulta indudable la alta motivación que genera en los estudiantes la introducción del cine en las aulas de Literatura, pues constituye un poderoso binomio educativo y cultural (Romea, 2003, 2011). Recordamos algunas de las películas en las que se descubre este diálogo entre la pluma del escritor y la cámara del director:

- El secreto de los Hermanos Grimm de Terry Gilliam. Hipotexto: Cuentos de los hermanos Grimm.

- Los santos inocentes de Mario Camus. Hipotexto: Miguel Delibes.

- Réquiem por un campesino español de Francesc Betriu. Hipotexto: Ramón J. Sender.

- La lengua de las mariposas de José Luis Cuerda. Hipotexto: Manuel Rivas.

- Hook de Steven Spielberg. Hipotexto: Peter Pan de J.M. Barrie.

- Al encuentro de Mr. Banks de John Lee Hancock. Hipotexto: Mary Poppins de P.L. Travers.

- El Cid, la leyenda de José Pozo (película de animación). Hipotexto: Cantar de Mio Cid.

En el ámbito didáctico, el visionado de las películas literarias favorece el desarrollo de diferentes tareas en las que se conjugan los elementos y códigos propios del lenguaje tanto cinematográfico como literario:

- Comparación de las versiones literaria y cinematográfica y análisis del tipo de reclamo o conexión intertextual: se respeta la versión literaria original, se recontextualiza la historia en otro tiempo y espacio, se realiza una adaptación libre de los personajes... 
- Estudio de épocas históricas y literarias a través de la ambientación de la película: espacios, decorado, fotografía, vestuario, sonidos...

- Análisis de la historia narrada en la película: resumen de la historia, cuestiones sobre el argumento, estudio del carácter de los personajes.

- Estudio de los elementos propios del lenguaje cinematográfico para la comprensión de la historia: asociación de colores y luz, conexión de la música con la trama argumental.

- Análisis de los recursos narrativos de la cámara: tipos de plano según el encuadre del personaje, tipos de ángulos en función de la orientación de la cámara, transición entre imágenes según los movimientos de la cámara.

- Dramatización de diferentes escenas de la película, reproduciendo el diálogo y movimientos de los personajes literarios.

\subsection{Los estilos en las artes}

Por último, al margen de estas relaciones bidireccionales literatura-música, literatura-pintura, literatura-cine, resulta pertinente conectar el conjunto de las artes implicadas en cada período histórico para procurar su estudio integrado y lograr una comprensión significativa de los diferentes elementos artísticos coincidentes. El currículo vigente muestra un especial interés por despertar en el alumnado esta visión holística de las artes, necesaria ya no solo desde el ámbito de la asignatura de Lengua Castellana y Literatura, sino desde otras materias artísticas y culturales como Literatura Universal, Música, Artes Escénicas y Danza o Fundamentos del Arte.

En esta línea, se proponen como ejemplo las siguientes temáticas de estudio, acompañadas de las obras literarias, pictóricas y musicales que ilustran el conjunto estilístico correspondiente:

- La naturaleza en el Romanticismo

- Literatura: El Pelayo de J. de Espronceda ("Envuelto en noche tenebrosa el mundo...").

- Pintura: Caminante sobre un mar de nubes de C.D. Friedrich.

- Música: Balada en Si menor de F. Liszt.

- El impresionismo y sus símbolos:

- Pintura: Impresión, Sol naciente de C. Monet.

- Música: "Claro de luna" (Suite bergamasque) de C. Debussy.

- Literatura: "Correspondencias" (Las flores del mal) de Ch. Baudelaire. 


\section{Conclusiones}

Una vez revisado el panorama actual que nos presenta el currículo vigente, tan solo nos queda conjugar los elementos de partida ya establecidos y dirigirlos convenientemente, según nuestros intereses receptivos, hacia una lectura plural interartística. Melopoiesis, ékfrasis y cine de literatura configuran tres senderos posibles en el acceso al estudio literario y en favor de la comprensión significativa de las obras por parte del alumnado. Igualmente, el trabajo integrado de las artes en el reconocimiento de los estilos permite el descubrimiento de elementos comunes y compartidos que se complementan y que, de otro modo, reflejarían un significado fragmentado.

El docente debe explotar en su aula las múltiples rutas e itinerarios que el lector de una obra hipertextual puede recorrer. El docente debe enfocar su quehacer hacia la formación del intertexto lector y el desarrollo de la competencia lectora. En definitiva, el docente debe conectar los diferentes códigos semióticos y revelar a su alumnado cómo los perfumes, los colores y los sonidos dialogan.

\section{Bibliografía:}

Barricelli, J.P. (1988). Melopoiesis: Approaches to the study of literature and music. New York: New York University Press.

Benítez, R. (2003). La paleta machadiana en Campos de Castilla. Espéculo. Revista de Estudios Literarios, $24 . \quad$ En http://www.ucm.es/info/especulo/numero24/paletam.html

Benítez, R., Vicente-Yagüe, Ma I., Jiménez, E. y Sánchez, C. (2015a). Lengua castellana $y$ literatura, ESO 1. Madrid: Edelvives.

Benítez, R., Vicente-Yagüe, Mª I., Jiménez, E. y Sánchez, C. (2015b). Lengua castellana y literatura, ESO 3. Madrid: Edelvives.

Bergez, D. (2011). Littérature et peinture. París: Armand Colin.

Ergal, Y.-M. y Finck, M. (dir.) (2014). Littérature comparée et correspondance des arts. Strasbourg: Presses Universitaires de Strasbourg.

Guerrero, P. (2008). Metodología de investigación en educación literaria (el modelo ekfrástico). Murcia: Diego Marín.

Jiménez, E. (2015). Niveles de la comprensión y la competencia lectora. Lenguaje y textos, 41, 19-25. 
Llort, V. (2011). La memoria de las musas. Aspectos metodológicos del comparatismo artístico. Barcelona: Tizona.

MECD (2015). Real Decreto 1105/2014, de 26 de diciembre, por el que se establece el currículo básico de la Educación Secundaria Obligatoria y del Bachillerato (BOE, $3 / 1 / 15)$.

Mendoza, A. (coord.). (2000). Lecturas de museo. Orientaciones sobre la recepción de relaciones entre la literatura y las artes. Barcelona: Universitat de Barcelona.

Mendoza, A. (2001). El intertexto lector. El espacio de encuentro de las aportaciones del texto con las del lector. Cuenca: Universidad de Castilla-La Mancha.

Mendoza, A. (coord.) (2012). Leer hipertextos. Del marco hipertextual a la formación del lector literario. Barcelona: Octaedro.

Romea, C. (2003). El impacto del discurso literario y audiovisual. La iconotextualidad como motivación del intertexto lector. En A. Mendoza y P. C. Cerrillo (coords.), Intertextos: aspectos sobre la recepción del discurso artístico (pp. 300-436). Cuenca: Ediciones de la Universidad de Castilla-La Mancha.

Romea, C. (2011). Cine de literatura. Poderoso binomio educativo y cultural. Lenguaje y textos, 34, 29-38.

Souriau, E. (1998). La correspondencia de las artes. México: Fondo de cultura económica.

Vicente-Yagüe Jara, $\mathrm{M}^{\mathrm{a}}$ I. de (2013). La intertextualidad literario-musical. Una estrategia didáctica para la animación a la lectura y la audición musical. Barcelona: Octaedro.

Vicente-Yagüe, Ma I. de (2015a). Fomento de la lectura: el plan lector. El canon formativo en la educación lectoliteraria. En P. Guerrero y M. T. Caro (coords.), Didáctica de la Lengua y Educación Literaria (pp. 297-303). Madrid: Pirámide.

Vicente-Yagüe, $M^{\mathrm{a}}$ I. de (2015b). Literatura e intertextualidad. Literatura y Música: un diálogo intersemiótico en el aula. En P. Guerrero y M. T. Caro (coords.), Didáctica de la Lengua y Educación Literaria (pp. 377-388). Madrid: Pirámide.

Wagner, R. (1952). La poesía y la música en el drama del futuro. Buenos Aires: EspasaCalpe. 